\title{
Application and Results of the TPM Methodology in a Factory for the Production of
} Agricultural and Earth-Moving Machines

\author{
Stefano Farné \\ Department of Industrial, Electrical, Computer and Biomedical Engineering, University of Pavia, Italy.
}

Copyright: @2020 Stefano Farné. This is an open access article distributed under the terms of the Creative Commons Attribution License, which permits unrestricted use, distribution, and reproduction in any medium, provided the original author and source are credited.

\section{ABSTRACT}

Total productive maintenance (TPM) is probably the most recent approach developed in the industrial field to address the problem of the global efficiency of plants and machines, which is one of the priority business factors for those companies in which the plant component is clashing with the ever more demanding requests from the market. These are requests for higher product quality, higher level of service and the need for greater flexibility, combined with the need not to increase operating and stock costs. Its growing importance is also linked to the significant trend of mechanization and automation of processes in place in companies. This article presents the fundamental aspects of the TPM methodology and it. application in a production plant of agricultural and earthmoving machinery, whose name is omitted for reasons of confidentiality.

Keywords: TPM, Total productive maintenance, Continuous improvement, Agricultural machinery, Earthmoving machinery.

\section{Introduction}

\section{The TPM methodology}

TPM (Total Productive Maintenance) is a proven manufacturing management tool for achieving excellence, in which the individual terms have the following meaning:

- Maintenance: activity aimed at maintaining the efficiency of the plants over time;

- Productive: which pursues the objective of improving the productivity of systems;

- Total: through the active involvement of all personnel and all functions.

The TPM corresponds to a total integration of the maintenance functions through preventive activities, the elimination of unexpected failures, defects and accidents, monitoring and continuous improvement, in order to pursue a totally productive maintenance.

At first glance, the "zero" philosophy might seem utopian, but the intrinsic concept is to recognize a cause of loss that inevitably becomes, for the company, an additional cost that the customer does not intend to recognize. The logical consequence is to implement the improvement actions necessary to make the cause of the identified loss "tend to zero".

The TPM attributes the burden of making timely decisions regarding maintenance interventions to the manufacturing management, placing the human factor at the center of its implementation and committing itself to promoting targeted training.

\section{Features and innovation}

The TPM pursues the goal of maximum reliability, at minimum cost (maintenance cost), using the Total Quality strategy in terms of: 
- continuous improvement, intended as daily improvement of the existing and not just as innovation;

- quality as a priority objective, where the term quality must be intended in the broadest sense: not only the quality of company performance and facilities, but also the quality of the organization and the quality of the people;

- wide involvement of all personnel in improvement actions;

- logic of preventing the causes of problems.

While there is normally a strong focus on considering and attacking the cost factors that impact in the short term (for example the purchase costs of a new plant, which are related to those of design and development), there is much less accountability on the factors that have long-term effects. The TPM is a total cost management system that pursues the goal of maximum total productivity; considers the Total Efficiency of the Plants as the main factor of productivity and identifies the fundamental component in the level of reliability of the same. Another innovative feature introduced by the TPM is the attention to prevention: the causes of the problems are essentially identified in "errors" committed during the operation or maintenance of the systems, or in the design of the same, and as such can be eliminated. The prevention system must affect all phases of the plant life cycle, from the management of the plants in operation to the design of new plants, passing through the structural improvement of existing plants.

Implementation therefore requires the involvement of the entire corporate structure, that is, of all functions and all levels; in this way, an integrated system for managing the reliability of the plants is favored, which allows each entity or person to carry out their role by finalizing it to the corporate objectives.

The ultimate goal of the TPM is to provide the company with a high design capacity in terms of total costs; the perspective of total costs requires that the company no longer reasons for sectoral efficiencies, but is entirely concentrated in the management of the process, on which all sectoral skills must converge and integrate. The high ability to manage and improve processes, in addition to the integration of all company sectors, also requires the development of adequate know-how; the whole process is therefore based primarily on the development and growth of personnel.

\section{Pillar structure}

The TPM addresses, according to a structured development plan, different issues including for each of them dedicated methodologies organized into pillars, and proposes an improvement management of maintenance and manufacturing (continuous improvement) according to a path of successive logical steps.

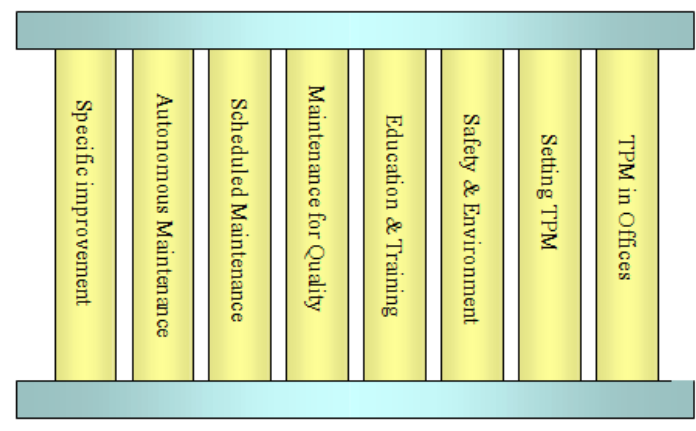

Figure 1 
A "pillar" is a team of people dedicated to eliminate a set of losses in compliance with the objectives set through the use of appropriate improvement methods. In practice, a pillar can be considered as a "toolbox", with very structured methods and procedures, which allow to address different specific issues. The pillars on the basis of which the TPM is organized are represented in the "temple" scheme, shown in figure 1.

\section{Specific improvement}

Starting from a detailed analysis of the losses of the individual plants, it addresses the resolution of specific problems through the activation of small interfunctional groups which, with the help of problem solving techniques, work on individual issues for short periods (5-10 weeks), attacking individual losses and improving the overall efficiency of the system.

\section{Autonomous Maintenance}

Through the direct involvement of production workers, it aims on the one hand to develop the knowledge of the operators themselves on the plant / machine they work with on a daily basis, and on the other hand to restore the initial conditions of the system by gradually eliminating degradation and therefore micro-stops.

\section{Scheduled Maintenance}

It aims to define the inspection and control standards and the types of maintenance activities necessary to define the maintenance plan for each production system and improve performance to obtain high availability and reliability at defined costs.

\section{Maintenance for Quality}

It is a set of methodologies to define and manage the conditions of production systems in order to prevent the appearance of defects, which is based on a well-structured data collection about the outputs of production system.

\section{Education \& Training}

It aims at defining and managing in a standardized way all training activities (in the classroom and on the job) that involve company staff. The goal of this pillar is to raise the technical skills of management and maintenance.

\section{Safety and Environment}

With the maintenance activities various improvements of the plants are implemented; when these improvements are made, it is absolutely necessary to check the safety conditions taking into account some elements such as: prevention of losses and dispersions, precautions against heat, respect for load capacities, vibrations and noise, electrical insulation.

\section{Setting TPM}

It aims at setting standards for design activities, at all levels.

\section{TPM in Offices}

As with production processes, office activities, from administrative to technical bodies, are also analyzed to define the appropriate standards and procedures for optimizing resources. 


\section{The TPM in an Agricultural and Earthmoving Machinery Plant}

The TPM in the plant in question was created to become a system that, embracing all company functions, from Quality Assurance to Safety and Environment, stimulates and guides improvement activities in a structured and organized way. The implemented TPM, in addition to share the objectives of involving all staff, of maximizing plant efficiency and of the centrality of team work in the improvement activity, places particular emphasis on the concepts of work organization. The point that more than any other has been kept in the foreground is that the road to improvement must be followed in small but continuous steps, with tenacity and steadiness. At the basis of everything there must be the belief that the improvement process is a dynamic phenomenon, without end, and that it represents an important opportunity for growth of the central element of every company: people. It is in this direction that attempts have been made to increase the TPM in the plant.

\section{Introduction and organization}

The TPM activity was introduced into the plant on two pilot groups (gearbox assembly and excavator mechanical carpentry) involving 40 workers and was expanded over time to involve all departments, for a total of over 450 people involved. As a natural continuation of the activity, the calculation of the TPM Index (annually) and the "Improvement Proposals" campaigns were introduced.

The Operational Plan shows the steps to be taken in the implementation of the TPM; it is divided into 2 macro-phases: the first (Phase I) aims at improving the Production Efficiency to be achieved through the reorganization of the work area according to the $3 \mathrm{~S}$ concepts; the second (Phase II, III, IV) aims at improving the efficiency of the machinery to be achieved through the implementation of an Autonomous Preventive Maintenance system.

\section{The first step: the $3 S$}

The $3 \mathrm{~S}$ technique derives from the $5 \mathrm{~S}$ methodology, developed in Japan; the name comes from three words starting with "S":

\section{SEIRI Elimination of the superfluous}

\section{SEITON Organization of the workplace}

\section{SEISO Cleaning}

The objectives of the $3 \mathrm{~S}$ are mainly:

- Eliminate dirt, unnecessary and confusion present in the work area, to make even the smallest problems "visible" and speed up actions;

- organize the workplace in a rational and structured way to facilitate the activities of employees;

- Maintain and improve cleaning standards, to make management simpler and more transparent;

It is important to point out that the $3 \mathrm{~S}$ are not a goal, but a work tool that must be part of daily habits to allow for improved efficiency in the work area. 


\section{The first S: Eliminate}

The activity that must be performed during the first $\mathrm{S}$ is: "Eliminate everything that is not strictly necessary for the activity that takes place in a work area". In its apparent simplicity, this phase is fundamental to be able to successfully implement the $2^{\text {nd }} \mathrm{S}$ and $3^{\text {rd }} \mathrm{S}$.

There are two operational phases:

1) distinguish the things that are useful from those that are not needed;

2) eliminate those that are not needed.

Once an unnecessary object has been identified, it must be immediately identified and taken out of the work area. The object is identified using the TPM Red Card, and this allows the team to evaluate the effectiveness of the first S activity (based on the number of cards issued) and to inventory what is removed, also for administrative purposes.

\section{The second S: Organize}

The second $\mathrm{S}$ is the natural continuation of the reorganization of the workplace, which began with the first $\mathrm{S}$. It is a very important phase since, following principles and rules, the reorganization of the work area is determined, which must be shared by everyone and that everyone will have to follow, but also because the efficiency of the workplace is built and, no less important, the level of safety is optimized.

The goal of the second $\mathrm{S}$ is:

- To define an address (therefore a location, a clear and precise method) for everything that must be in work area;

- To make available and easily accessible all that is needed, in the manner and in the necessary quantities.

The strategic point of the second S can be summed up in the sentence: "a place for everything, everything in its place and in the right quantity".

\section{The third S: Clean}

The third S establishes the rules and the methods for maintaining the workplace, periodically removing dirt (dust, shavings, oil, etc ...) to keep the workplace clean and safe.

The third S represents the final phase of the reorganization of the work area in order to improve its safety and efficiency; it is that phase that allows to understand why a certain type of dirt is generated and to implement the appropriate preventive actions to the formation of the same.

The goal of the third $\mathrm{S}$ is to make a map of the department area, indicate the workstations with the staff responsible for cleaning the area and prepare the cleaning calendar.

The second step: Prevention_Visibility / Cleaning_Inspection_Lubrication

The PV / PIL activity ("Prevention_Visibility" / "Cleaning_Inspection_Lubrication") represents the phase in which the final objective is to improve the efficiency of the machinery by foreseeing the onset of anomalous operating conditions, through cleaning, inspection and scheduled lubrication, making visible everything that needs to be 
checked / inspected. It is therefore necessary to remove the sources / causes of contaminants (shavings, oil ...), the inaccessible or difficult areas for maintenance and improve the "visibility of problems" in the various areas, providing training on the principles of cleaning, inspection and lubrication of machinery.

At the operational level there are two phases:

1) preparation phase: the team leader, the machine operator, the maintenance technician and the technologist prepare the machine card for the Cleaning, Inspections and Scheduled Lubrications.

2) action phase: the Scheduled Cleaning, Inspection and Lubrication calendar is carried out, following the information reported on the machine card to achieve the PV / GDP target.

\section{The third step: Autonomous Inspection Maintenance}

The goal of M-I-A ("Autonomous Inspection Maintenance") is to improve the overall efficiency of the machinery, reducing "6 major losses":

\section{1) Losses for Faults}

Losses due to faults are those resulting from a machine stop; the downtime is represented by the intervention and repair time by the Maintenance; it happens much more often than it is believed that failures are caused by improper use of the systems.

\section{2) Losses for Equipment and Adjustments}

Losses for tooling and adjustments include all losses caused by tool and material changes and machine set-up. The company trend is that characterized by a production with high differentiation of products and, therefore, smaller batches; There can also be multiple product type changes per day, so these losses are increasingly important.

\section{3) Losses for No-Load Operation and Microstops}

Microstops result from machine problems that cannot be solved, and try to be buffered, due to the pace of production. They are often underestimated and overlooked but, being in large numbers, they cause surprisingly large losses.

\section{4) Speed Reduction Losses}

The speed of the machines often does not correspond to the recommended standard for various reasons. Recurring problems, for example, are a loosening of the V-belt or a lack of knowledge on how to act on the speed according to the load conditions.

\section{5) Losses for Defects and Repairs}

Losses due to defects and repairs are those due to the production of defective parts, often due to the operator's inattention. Even if the defects are low, unnecessary costs are incurred in terms of materials and labor.

\section{6) Loss of Yield on Goodwill}

The losses in performance at start-up are similar to those caused by adjustments after tooling, and are due to the initial transient of all the machines. 
To reduce all these losses it is necessary that the machine operator, through a systematic analysis and control of the system, records the anomalies found and the machine stops detected, on a special card, after which the function responsible for analyzing these anomalies will bring, where necessary, the appropriate improvement actions to the plant.

To evaluate and monitor the overall efficiency of the machinery, an indicator is calculated monthly, the O.E.E. (Overall Equipment Effectiveness) which represents the percentage of time used to transform semi-finished products into compliant products, compared to the total time taken.

\section{The fourth step: Continuous Improvement}

The Continuous Improvement is a path to be completed in "small steps", and means learning to use the tools of the TPM (3S, P / V \& PIL, MIA) and adopting a behavior (discipline and respect for the rules) that allows, first of all, to pursue the improvement of the efficiency of the workplace, and, subsequently, of the efficiency of the machinery by creating a safe, quality and efficient work area.

"Improvement Proposal" means any suggestion aimed at improving plant and product processes, in relation to the aspects: Quality, Safety, Environment, Cost Reduction, Plants and Workplace.

The "Proposals for Improvement" project is an initiative launched by the company as part of the prevention activities in order to improve the service to the customer and optimize the result of the business process; all workers employed by the company can participate in this project. To each aspect (topic) affected by the proposal it is assigned a score with the help of the evaluation tables, which take into account the level of improvement made following the implementation of the proposal.

Each improvement proposal made is rewarded by a letter of commendation from the Head of the function, and with a cash prize, the amount of which depends on the score attributed to it; the awarding mechanism provides for an individual ranking with points, and the points assigned to each proposal made are added to the proposer's score in the individual ranking.

Every year, the top 3 winners are paid a sum of money, and the best proposal in each of the following categories is also awarded: Safety / Environment, Cost Reduction, Quality, Plants/Workplace. The progress of the improvement proposals is assessed monthly and compared with the Target established by the Management Committee.

\section{Performance parameters and indicators}

"Improving" is very important, but it is equally important to measure what an improvement action has produced, because "what cannot be measured cannot be improved". The most important parameters (with related indicators) that are taken into consideration are the red cards, the set free space, the "added value" and "non-added value" operations and the TPM Index.

\section{Red Cards}

The "Red Card" is the tool used to identify (during the first S activity, but not only) all the objects not necessary for the activity carried out in a given workplace. The more Red Cards are issued, the more effective the identification 
and subsequent disposal of "unnecessary" objects has been; this activity also generates value, in the sense that disused objects from one area are in many cases reusable in other areas, resulting in savings on the purchase of materials.

\section{Set free space}

The activity of eliminating "unnecessary" material in a given area generates, to varying degrees, "free" space. This set free space makes it possible to rationalize the logistical-production flows of the area itself and also represents a possible saving. In fact, areas of the workshop no longer used can be used for other processes, with consequent savings on the possible construction of additional space, or they can simply not be "served", with a consequent reduction in lighting, heating, ordinary maintenance, network costs of compressed air, gas, water, etc ...

\section{"Value added" operations}

They represent the number of hours spent daily in operations that "create value" for the product, which essentially are the operations of the work cycle.

\section{"Non - added value" operations}

They represent the number of hours spent daily in operations that "do not create value" for the product; they are often operations that cannot be completely reduced but which, in most cases, can be significantly reduced. The non - value added macro operations are: handling, repairs, lack of material, completions, machine / plant downtime.

\section{TPM Index}

In addition to evaluate the individual activities carried out during the TPM, there is the need to measure the "overall" performance of a team or department; for this purpose a performance indicator called TPM Index is used, which considers 5 main aspects: accidents, quality, efficiency, continuous improvement and improvement proposals. A reference target is established on each aspect that can be customized for each group, and every month the calculation is performed on each aspect and the final values are compared with those of the target.

This indicator allows the TPM team to evaluate the performance of each individual group both overall and for each aspect, giving the possibility to carry out corrective actions; it also makes it possible to make a comparison between the various groups as the data are homogeneous; team rankings are calculated and displayed on a monthly basis.

\section{Achieved results}

In the first years of application of the TPM, very important results were achieved: the "non-added value hours" (O.V.N.A.) decreased significantly, reducing the costs of the plant. The percentage of "added value hours" (O.V.A), equal to approximately $78 \%$ of the total hours at the beginning of the TPM activity, has increased year on year to reach $85 \%$ three years later; this improvement was possible thanks to the decrease in: material handling times, repairs, use of forklift drivers, operator errors and machine downtime. In the first four years of applying this method, 9500 hours were therefore "saved", half of which thanks to the reduction in the number of forklift drivers. Table 1 summarizes these results. 


\begin{tabular}{|c|c|c|c|c|c|c|c|}
\hline & O.V.A. & O.V.N.A. & Movem. & Repair & Forklift & Oper. & F/Mach. \\
\hline Start Value & $78 \%$ & $22 \%$ & $1,40 \%$ & $0,64 \%$ & $6,50 \%$ & $10,30 \%$ & $\mathbf{3 , 4 0 \%}$ \\
\hline Final Value & $85 \%$ & $15 \%$ & $0,30 \%$ & $0,32 \%$ & $2,50 \%$ & $9,70 \%$ & $\mathbf{1 , 8 0 \%}$ \\
\hline Difference & $7,67 \%$ & $-7,67 \%$ & $-1,11 \%$ & $-0,32 \%$ & $-4,00 \%$ & $-0,60 \%$ & $\mathbf{- 1 , 6 3 \%}$ \\
\hline $\begin{array}{l}\text { Correspon } \\
\text { ding hours }\end{array}$ & $\mathbf{9 5 0 0}$ & $\mathbf{- 9 5 0 0}$ & $\mathbf{- 1 3 6 9}$ & $\mathbf{- 4 0 1}$ & $\mathbf{- 4 9 6 0}$ & $\mathbf{- 7 4 5}$ & $\mathbf{- 2 0 2 5}$ \\
\hline
\end{tabular}

Table 1

The improvements obtained were also quantified by enhancing the saving / recovery of materials and space, and the increase in efficiency (Table 2); from the beginning to the end of the fourth year, the estimated savings were over 850,000 euros and more than half of this figure is due to the increase in efficiency.

\begin{tabular}{|c|c|c|c|c|}
\hline & Space & Materials & Efficiency & Total \\
\hline End of 1st year & $5004.47 €$ & $21281.74 €$ & $17736.27 €$ & $\mathbf{4 4 0 2 2 . 4 8} €$ \\
\hline End of 2nd year & $29453.53 €$ & $100975.74 €$ & $69489.63 €$ & $\mathbf{1 9 9 9 1 8 . 9 1} €$ \\
\hline End of 3rd year & $60255.03 €$ & $126685.74 €$ & $240370.79 €$ & $\mathbf{4 2 7 3 1 1 . 5 6} €$ \\
\hline End of 4th year & $\mathbf{1 0 4 0 9 2 . 1 5} €$ & $\mathbf{1 9 0 0 1 4 . 7 2} €$ & $\mathbf{5 5 8 5 6 7 . 3 9} €$ & $\mathbf{8 5 2 6 7 4 . 2 5} €$ \\
\hline
\end{tabular}

Table 2

Subsequently, the evaluation of the plant's performance was carried out by evaluating the reduction in costs obtained through the improvement proposals (Table 3). Thanks to the application of the proposals presented, the number of shifts lost due to breakdowns and micro-stops has significantly decreased: the percentage of shifts lost compared to those worked, which before the introduction of the improvement proposals campaign was equal to $8.3 \%$, after seven years it dropped to $4.5 \%$

\begin{tabular}{|l|c|c|c|}
\hline & Failures & Microstops & Failures + Microstops \\
\hline End of 1st year & $6,2 \%$ & $2,1 \%$ & $\mathbf{8 , 3 \%}$ \\
\hline End of 2nd year & $4,0 \%$ & $2,5 \%$ & $\mathbf{6 , 4 \%}$ \\
\hline End of 3rd year & $3,6 \%$ & $2,4 \%$ & $\mathbf{6 , 1 \%}$ \\
\hline End of 4th year & $3,0 \%$ & $1,8 \%$ & $\mathbf{4 , 8 \%}$ \\
\hline End of 5th year & $\mathbf{2 , 9 \%}$ & $\mathbf{1 , 6 \%}$ & $\mathbf{4 , 5 \%}$ \\
\hline
\end{tabular}

Table 3 
The campaign of improvement proposals made it possible to continue the positive trend of cost reduction started with the introduction of the TPM (Table 4), obtaining a cost reduction, in the first four years, of 381,187 Euros, a figure far higher than the 85,540 Euros spent to pay for the implemented proposals.

\begin{tabular}{|c|c|c|c|c|}
\hline & $\begin{array}{c}\text { End of 1st } \\
\text { year }\end{array}$ & $\begin{array}{c}\text { End of 2nd } \\
\text { year }\end{array}$ & $\begin{array}{c}\text { End of 3rd } \\
\text { year }\end{array}$ & $\begin{array}{c}\text { End of 4th } \\
\text { year }\end{array}$ \\
\hline Efficiency & $46495 €$ & $24184 €$ & $9517 €$ & $\mathbf{2 1 9 4} €$ \\
\hline Loss Recovery & $37731 €$ & $48279 €$ & $8953 €$ & $\mathbf{2 4 9 4 0 €}$ \\
\hline Other & $8461 €$ & $93128 €$ & $58757 €$ & $\mathbf{1 8 5 4 8} €$ \\
\hline Total & $92687 €$ & $165591 €$ & $77227 €$ & $\mathbf{4 5 6 8 2} €$ \\
\hline Paid proposals & $\mathbf{2 0 9 5 8} €$ & $\mathbf{2 4 6 2 5} €$ & $\mathbf{2 2 9 7 1} €$ & $\mathbf{1 6 9 8 6} €$ \\
\hline
\end{tabular}

Table 4

From the data analysis it is possible to see how the cost reduction due to the improvement of efficiency constitutes only a small part of the total; this percentage is decreasing very rapidly, going from $50.16 \%$ recorded at the beginning to $4.80 \%$ after seven years of implementation (Figure 2): this is due to the fact that the margins for improving efficiency decrease year by year, given the excellent levels achieved in recent years in every sector of the plant, thanks to the application of the TPM.

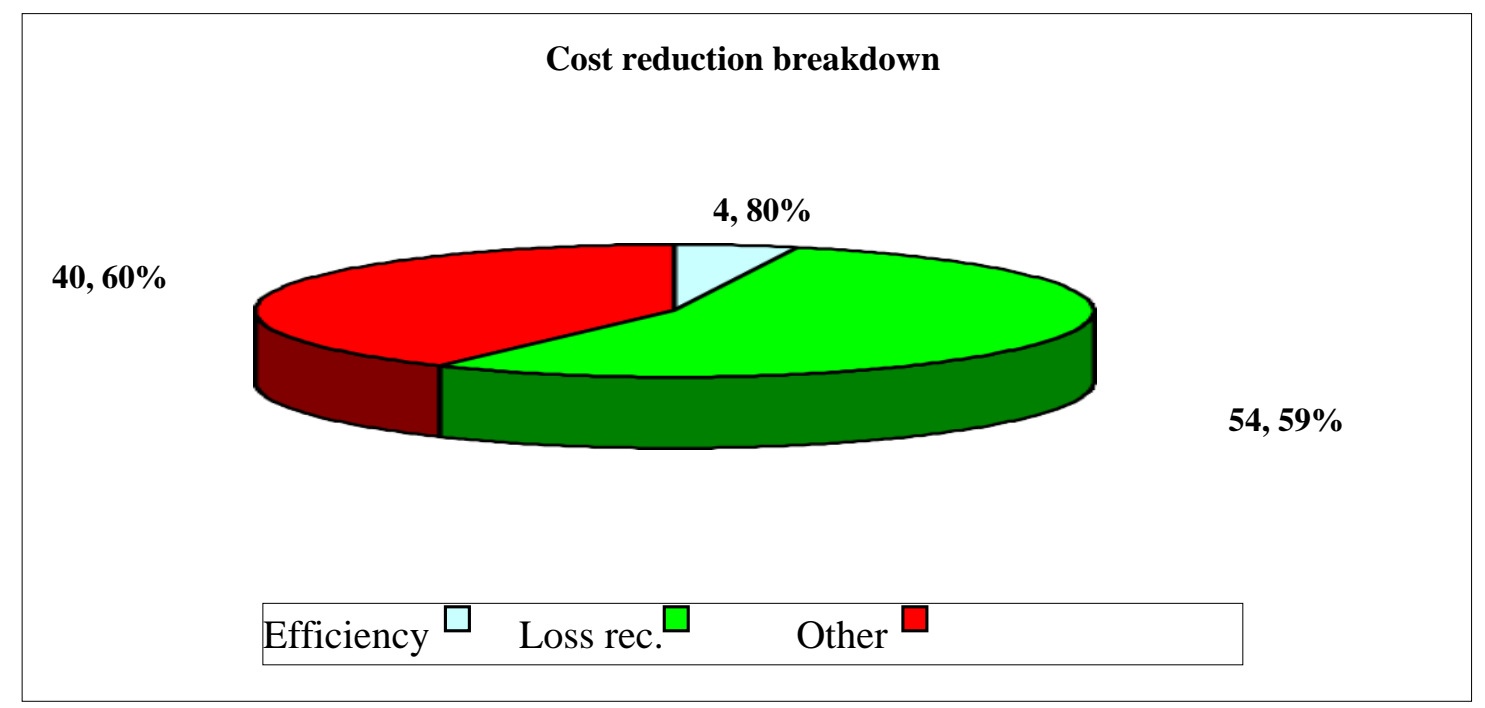

Figure 2

Although very important, the greatest competitive advantage achieved consists in the high ability to continuously improve the processes, in order to meet the ever-increasing needs and expectations of the market.

\section{Conclusions}

From the study carried out, it is clear what are the advantages that can be obtained in a company by applying the TPM methodology; difficulties are encountered, especially to overcome people's resistance to change in mentality, 
Asian Journal of Basic Science \& Research

and additional costs must be incurred, but the obtainable advantages are considerable: the reduction of costs and the improvement of productivity and efficiency are very important, but the increased flexibility, a greater involvement of personnel and the change towards a mentality aimed at the continuous improvement are even more so, as they can become the fundamental factors for determining the success of a company in an increasingly demanding market.

\section{Bibliography}

S. Nakajima. Introduction to Total Productive Maintenance. (1994) Productivity Press Inc.

L. Furlanetto (a cura di). Manuale di manutenzione degli impianti industriali e dei servizi. (1999) Fr. Angeli Ed.

L. Furlanetto, A. Arata Andreani. Organizzazione snella. Esperienze nell'industria e nei servizi. (2004) Franco Angeli Ed.

R. Cigolini, F. Turco. Total productive maintenance practices : a survey in Italy. (1997) Journal of quality in Maintenance Engineering. MCB Press www.managementsupport.org

Abhishek Jain, Rajbir Bhatti , Harwinder Singh, Total productive maintenance (TPM) implementation practice: A literature review and directions, International Journal of Lean Six Sigma ISSN: 2040-4166, 29 July 2014.

Attri, R., Grover, S., Dev, N. et al. Analysis of barriers of total productive maintenance (TPM). Int J Syst Assur Eng Manag 4, 365-377 (2013). https://doi.org/10.1007/s13198-012-0122-9

F.T.S.Chan, H.C.W.Lau, R.W.L.Ip, H.K.Chan, S.Kong, Implementation of total productive maintenance: A case study, International Journal of Production Economics, Volume 95, Issue 1, 28 January 2005, Pages 71-94.

Ireland, F. and Dale, B.G. (2001), "A study of total productive maintenance implementation", Journal of Quality in Maintenance Engineering, Vol. 7 No. 3, pp. 183-192. https://doi.org/10.1108/13552510110404495

Maggard, Bill N; Rhyne, David M., Total productive maintenance: A timely integration of production and maintenance, Inventory Management Journal; Alexandria Vol. 33, Fasc. 4, (Fourth Quarter 1992): 6.

Ahuja, I.P.S. and Khamba, J.S. (2008), "Total productive maintenance: literature review and directions", International Journal of Quality \& Reliability Management, Vol. 25 No. 7, pp. 709-756.

https://doi.org/10.1108/02656710810890890

Kathleen E.McKone, Roger G.Schroeder, Kristy O.Cua, Total productive maintenance: a contextual view, Journal of Operations Management Volume 17, Issue 2, January 1999, Pages 123-144. 